\title{
Primary Pancreatic Lymphoma: The Role of Surgical Treatment
}

\author{
Hiroki Sugishita Yuji Watanabe Yuji Yamamoto \\ Motohira Yoshida Koichi Sato Atushi Horiuchi \\ Kanji Kawachi
}

Department of Organ Regenerative Surgery, Ehime University School of Medicine, Toon, Japan

\section{Key Words}

Primary pancreatic lymphoma · Surgical treatment · Youngest case

\begin{abstract}
Primary pancreatic lymphoma (PPL) is a rare disease that is difficult to diagnose preoperatively. We describe the youngest case of PPL treated by surgical excision and chemotherapy. A 16-year-old male presented with abdominal pain and jaundice. Abdominal computed tomography showed a $3.0 \times 4.5 \mathrm{~cm}$ homogeneously enhanced mass localized between the inferior vena cava and pancreatic head; the common pancreatic duct was dilated and the common bile duct was stenosed. Magnetic resonance imaging findings showed a $4.5 \mathrm{~cm}$ tumor localized between the inferior vena cava and pancreatic head with low signal intensity on T1W images and high intensity on T2W images, which enhanced inhomogeneously. Endoscopic retrograde cholangiopancreatography findings were compatible with smooth stenosis of the common bile duct. He was diagnosed as pancreatitis secondary to pancreatic tumor and pylorus-preserving pancreaticoduodenectomy was performed. Postoperative diagnosis was PPL and chemotherapy was performed. After 4 years of treatment he has no signs of recurrence.
\end{abstract}

\section{Introduction}

Primary pancreatic lymphoma (PPL) is a rare disease constituting less than $0.5 \%$ of all pancreatic malignancies [1], and PPL is difficult to diagnose preoperatively even by various modalities. Regarding the treatment for PPL, chemotherapy including R-CHOP is considered as standard. On the other hand, for the patient who had a symptom caused by obstruction of biliary tract, surgical treatment was effective [2]; furthermore, a response rate of $100 \%$ was obtained by successful resection [3], and the long-term survival rate with combination of surgical treatment and adjuvant chemotherapy was superior to current chemotherapy [4]. 
Herein we present a case of pancreas head tumor managed as tumor-forming pancreatitis, who proved to have PPL after pylorus-preserving pancreaticoduodenectomy, and chemotherapy was performed. After 4 years of combined treatment, the patient has no signs of recurrence. For the patient with PPL, surgical treatment combined with chemotherapy can be an effective treatment contributing to long-term survival.

\section{Case Report}

A 16-year-old male with an unremarkable past medical history presented with abdominal pain and jaundice. The patient's laboratory findings on admission included a white blood cell count of $4.5 \times$ $10^{3} / \mathrm{\mu l}$, hemoglobin of $15.8 \mathrm{~g} / \mathrm{dl}$, a platelet count of $19.0 \times 10^{4} / \mu \mathrm{l}$, creatinine of $1.0 \mathrm{mg} / \mathrm{dl}$, total protein of $7.6 \mathrm{~g} / \mathrm{dl}$, total bilirubin of $8.1 \mathrm{mg} / \mathrm{dl}$, and liver enzymes including a SGOT of $157 \mathrm{IU} / \mathrm{l}$, SGPT of $312 \mathrm{IU} / \mathrm{l}$, amylase of 2,605 IU/l, C-reactive protein of $\leq 0.3 \mathrm{mg} / \mathrm{dl}$, and DUPAN-2 of $970 \mathrm{U} / \mathrm{ml}$.

Abdominal computed tomography (CT) showed a $3.0 \times 4.5 \mathrm{~cm}$ homogeneously enhancing mass (fig. 1a) localized between the inferior vena cava and pancreatic head. The common pancreatic duct was dilated and the common bile duct was stenosed (fig. 1b). Magnetic resonance imaging (MRI) findings showed a $4.5 \mathrm{~cm}$ tumor localized between the inferior vena cava and pancreatic head with low signal intensity on T1W images and high intensity on T2W images (fig. 2), which enhanced inhomogeneously. Endoscopic retrograde cholangiopancreatography (ERCP) findings were compatible with smooth stenosis of the common bile duct and main pancreatic duct without signs of infiltration (fig. 3).

On physical exam, the patient's bulbar conjunctiva were icteric, but the tumor was not palpable. The patient was diagnosed with tumor-forming pancreatitis and pylorus-preserving pancreaticoduodenectomy was performed. Histopathology showed small tumor cells without cell adhesion or tissue structure proliferation (fig. $4 \mathrm{a}$ ), and immunochemical staining was positive for B cell markers CD20 and CD79a and negative for T cell marker CD10 (fig. 4b-d). Pathological examination was compatible with Hodgkin's diffuse B cell lymphoma.

The patient's postoperative course was uneventful and he was discharged from the hospital on the 28th postoperative day. A month later, he was readmitted for chemotherapy with R-CHOP. He has had no signs of recurrence in the 4 years since the surgery.

\section{Discussion}

PPL is a rare disease constituting less than $0.5 \%$ of all pancreatic malignancies, and less than $2 \%$ of extranodal lymphomas [1]. Most cases are intermediate or high grade non-Hogdkin's lymphoma of diffuse large B cell type. PPL demonstrates a male preponderance (male to female ratio of 7:1) and the mean age at presentation is 55.0 years [5]. Saif [6] reported that the major presenting symptoms are abdominal pain in $83 \%$ of patients and abdominal mass in $58 \%$ of cases. Other symptoms include jaundice, reflux, weight loss, bowel obstruction and diarrhea [5]. In our case, the patient presented to our hospital with abdominal pain and jaundice.

A survey of the literature reveals that our patient is the youngest case of resected PPL in our country. The diagnostic criteria for PPL, as indicated by Dawson et al. [7], include: (a) neither superficial lymphadenopathy nor enlargement of mediastinal lymph nodes on chest radiography; (b) a normal leukocyte count on peripheral blood smear; (c) the main tumor mass confined to the pancreas with lymph node involvement confined to the peripancreatic region; (d) no hepatic or splenic involvement. Our case demonstrates most of the above criteria.

$\mathrm{CT}$ and ultrasound are the most common imaging techniques used for the detection of PPL. Ultrasound usually shows a homogeneous, hypoechoic mass [8] and CT commonly 
demonstrates a homogeneous lesion with attenuation that is less than that of muscle [9]. Merkle et al. [10] found CT especially helpful in the differential diagnosis of a tumor localized to the pancreatic head. They reported that the combination of a bulky localized tumor in the pancreatic head without significant dilatation of the main pancreatic duct suggests a diagnosis of pancreatic lymphoma over adenocarcinoma. Enlarged lymph nodes below the level of the renal veins with invasive tumor growth not respecting anatomic boundaries and infiltrating either retroperitoneal or upper abdominal organs and the gastrointestinal tract are additional reliable findings of PPL [10]. Concerning ERCP findings, normal duct, ductal displacement, mild ductal stenosis and stricture of the main pancreatic duct were found in $30,10,50$, and $10 \%$ of patients, respectively [10]. Regarding MRI, the mass usually shows low signal intensity on T1-weighted images and homogeneously high signal intensity on T2-weighted images [11], similar to our findings.

For a definitive diagnosis, CT-guided biopsy is usually necessary, and Webb et al. [12] report that CT-guided biopsy was performed for 4 cases of PPL, and in all cases, definitive diagnosis was obtained. However, Tuchek et al. [13] reported that it was difficult to perform CT-guided biopsy safely and, therefore, this method should be performed only by trained physicians in tertiary centers.

Regarding treatment, anthracycline-based chemotherapy is the standard treatment for non-Hodgkin's lymphoma, and six to eight cycles of R-CHOP are usually performed for patients of all ages [14]. On the other hand, Kevin et al. [15] reported that it is difficult to obtain long-term survival by chemotherapy alone, and Battula et al. [4] reported that the 5 -year survival rate of PPL treated with current chemotherapy was less than $50 \%$, and its rate was inferior to combination of surgical procedure and chemotherapy, therefore they concluded that pancreaticoduodenectomy may have a therapeutic role in association with chemotherapy. As another adaptation of choice surgical procedure, Lin et al. [2] reported that patients with biliary tract or gastrointestinal obstruction should receive biliary or gastric bypass to alleviate symptoms. In our case, the patient was not diagnosed with PPL preoperatively, but since there was obstruction of the biliary tract, pylorus-preserving pancreaticoduodenectomy was performed. His postoperative course was uneventful and 8 cycles of R-CHOP were performed with no signs of recurrence after 4 years. It is, therefore, important to choose the appropriate treatment depending on disease progression and the patient's condition. 


\begin{tabular}{r|l|l|l} 
Case Reports in & $\begin{array}{l}\text { Case Rep Gastroenterol 2010;4:104-110 } \\
\text { D0I: 10.1159/000283405 }\end{array}$ & Published online: March 17, 2010 & $\begin{array}{l}\text { O 2010 S. Karger AG, Basel } \\
\text { ISSN 1662-0631 } \\
\text { www.karger.com/crg }\end{array}$ \\
\hline
\end{tabular}

Fig. 1. Abdominal CT findings. A $3.0 \times 4.5 \mathrm{~cm}$ tumor was localized between the inferior vena cava and pancreatic head which enhanced homogeneously with contrast administration (a). The common pancreatic duct was dilated (arrow) and the common bile duct was stenosed (b).

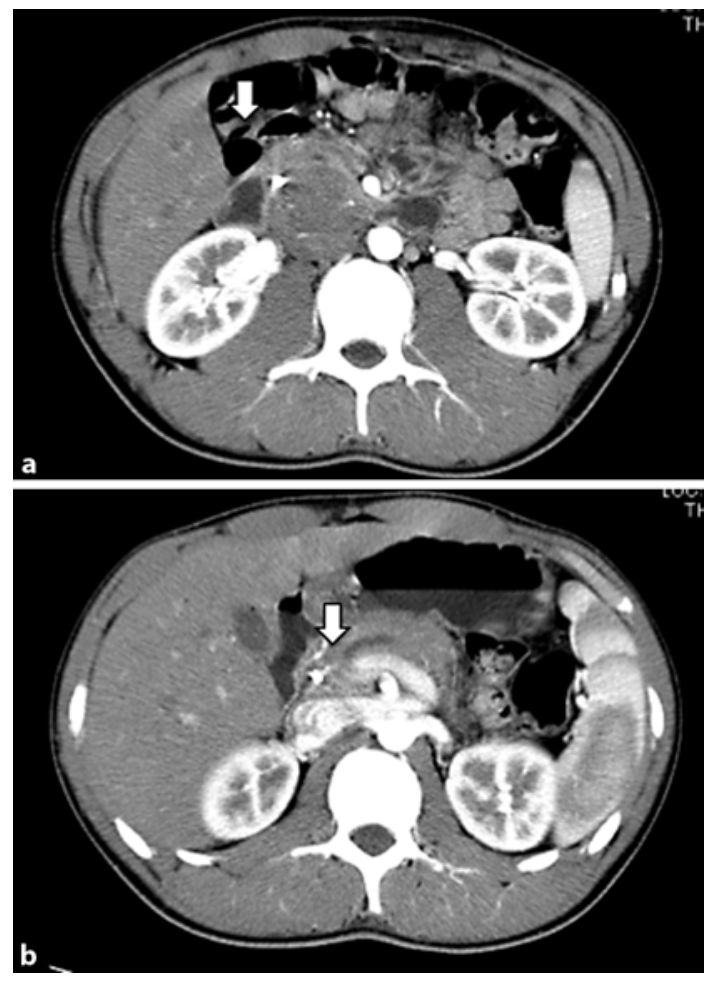




\begin{tabular}{r|l|l|l} 
Case Reports in & $\begin{array}{l}\text { Case Rep Gastroenterol 2010;4:104-110 } \\
\text { D0I: 10.1159/000283405 }\end{array}$ & Published online: March 17, 2010 & $\begin{array}{l}\text { O 2010 S. Karger AG, Basel } \\
\text { ISSN 1662-0631 } \\
\text { www.karger.com/crg }\end{array}$ \\
\hline
\end{tabular}

Fig. 2. MRI findings. There was a $4.5 \mathrm{~cm}$ tumor localized between the inferior vena cava and the pancreatic head which demonstrated low signal intensity on T1-weighted images (a) and high signal intensity on T2-weighted images and which enhanced inhomogeneously (b).
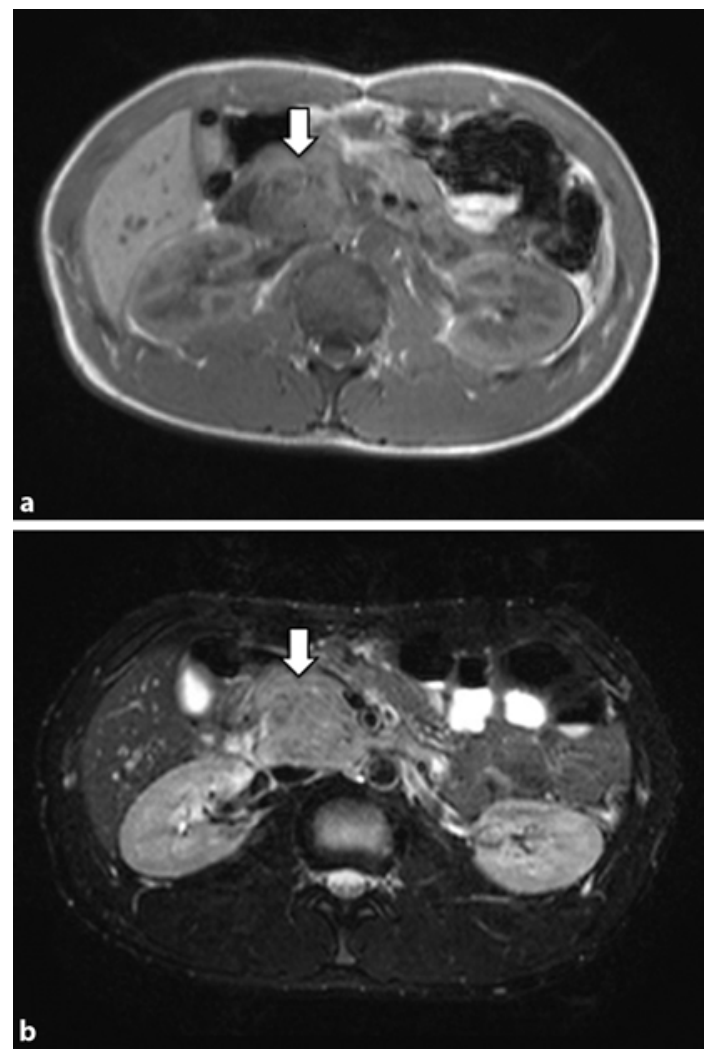

Fig. 3. ERCP findings. The common bile duct and the main pancreatic duct were stenosed smoothly without findings of infiltration (arrow).

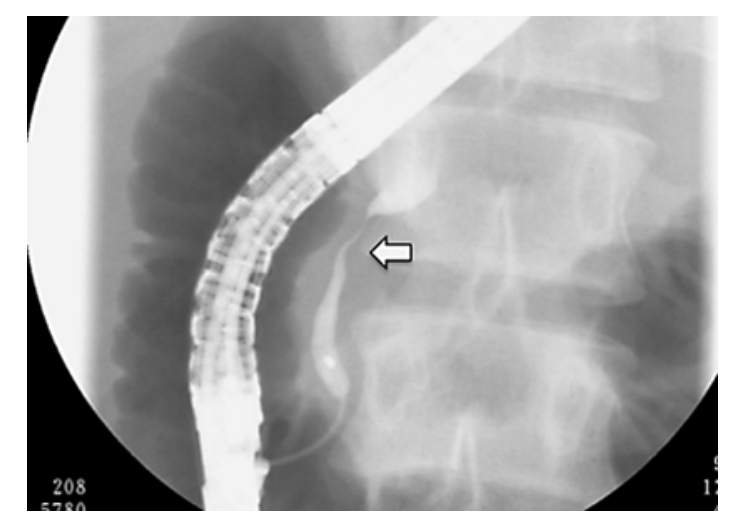




\begin{tabular}{r|l|l|l} 
Case Reports in & $\begin{array}{l}\text { Case Rep Gastroenterol 2010;4:104-110 } \\
\text { D0I: 10.1159/000283405 }\end{array}$ & Published online: March 17, 2010 & $\begin{array}{l}\text { O 2010 S. Karger AG, Basel } \\
\text { ISSN 1662-0631 } \\
\text { www.karger.com/crg }\end{array}$ \\
\hline
\end{tabular}

Fig. 4. Pathology findings. Histopathology showed small tumor cells without cell adhesion or tissue structure proliferation $(\mathbf{a}, \mathrm{HE}, \times 400)$, and immunochemical staining was positive for B cell markers CD20 and CD79 and negative for T cell marker CD10 (b-d, $\times 400)$ compatible with the diagnosis of Hodgkin's diffuse B cell lymphoma.
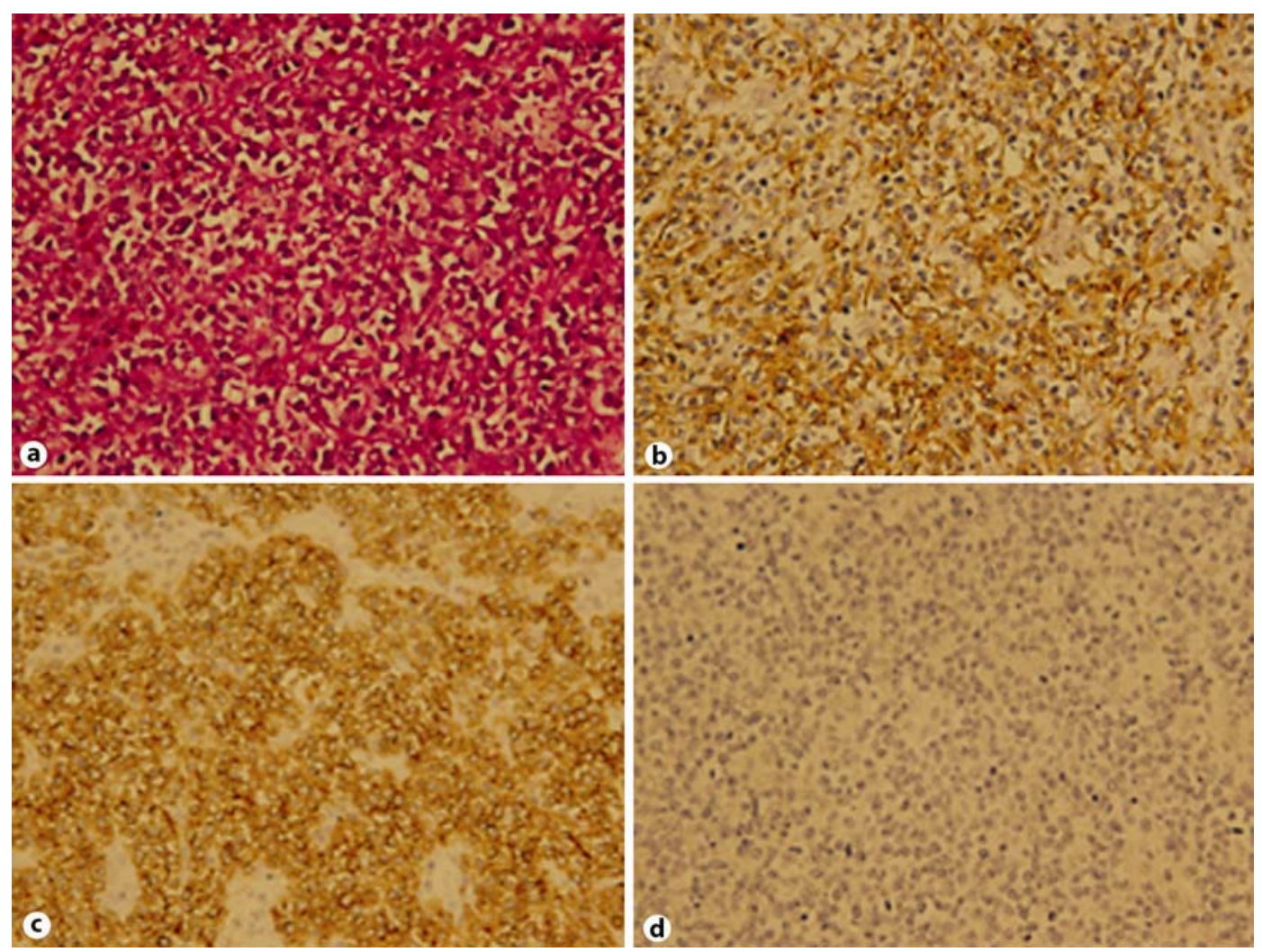


\section{References}

1 Arcari A, Anselmi E, Bernuzzi P, Berta R, Lazzaro A, Moroni CF, Trabacchi E, Vallisa D, Vercelli A, Cavanna L: Primary pancreatic Lymphoma: report of five cases. Haematologica 2005;90:ECR09.

-2 Lin H, Li SD, Hu XG, Li ZS: Primary pancreatic lymphoma: report of six cases. World J Gastroenterol 2006;12:5064-5067.

-3 Theodore L, Evangelos PM, Dimitrios T, Irene N, Gabriel K, Anastasios M: A role for surgery in primary pancreatic B-cell lymphoma: a case report. J Med Case Reports 2008;2:167.

-4 Battula N, Srinivasan P, Prachalias A, Rela M, Heaton N: Primary pancreatic lymphoma: diagnostic and therapeutic dilemma. Pancreas 2006;33:192-194.

5 Nayer H, Weir EG, Sheth S, Ali SZ: Primary pancreatic lymphomas: a cytopathologic analysis of a rare malignancy. Cancer 2004;102:315-321.

6 Saif MW: Primary pancreatic lymphomas. JOP 2006;7:262-273.

7 Dawson IM, Cornes JS, Morson BC: Primary malignant lymphoid tumors of the intestinal tract. Report of 37 cases with a study of factors influencing prognosis. Br J Surg 1961;4:80-89.

-8 Cario E, Runzi M, Metz K, Layer P, Goebell H: Diagnostic dilemma in pancreatic lymphoma. Int J Pancreatol 1997;22:67-71.

-9 Prayer L, Schurawitzki H, Mallek R, Motsbeck G: CT in pancreatic involvement of non-Hodgkin lymphoma. Acta Radiol 1992;33:123-127.

10 Merkle EM, Bender GN, Brambs HJ: Imaging findings in pancreatic lymphoma: differential aspects. AJR Am J Roentgenol 2000;174:671-675.

11 Masui T, Katayama M, Kobayashi S, Shimizu S: MR imaging of primary malignant lymphoma of the pancreas. Radiat Med 2005;23:213-215.

12 Webb TH, Lillemoe KD, Pitt HA, Jones RJ, Cameron JL: Pancreatic lymphoma. Is surgery mandatory for diagnosis or treatment? Ann Surg 1989;209:25-30.

13 Tuchek JM, Jong SAD, Pickelman J: Diagnosis, surgical intervention, and prognosis of primary pancreatic lymphoma. Ann J Surg 1993;59:513-518.

14 Practice guidelines in Oncology-v.2. 2006: National Comprehensive Cancer Network; non Hodgkin's lymphoma.

15 Behrns KE, Sarr MG, Strickler JG: Pancreatic lymphoma: is it a surgical disease? Pancreas 1994;9:662-667. 